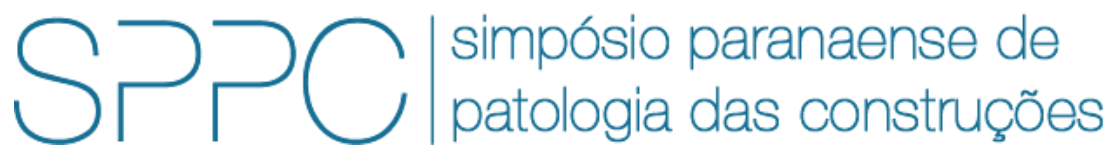

ISSN 2526-7248 artigo 2SPPC1036, pp. 435-447, 2017

\title{
Avaliação da resistência à tração de barras de aço CA-50 expostas à região litorânea
}

\author{
Demétro Filho, Alexandre de Azevedo ${ }^{1}$; Melo, Antônio Carlos de Albuquerque ${ }^{2}$; Andrade, Tiago Lins \\ C. de $0^{3}$ e Costa e Silva, Angelo Just da ${ }^{4}$ \\ ${ }^{1}$ Engenheiro Civil, Mestre, Tecomat Engenharia Ltda, alexandre@tecomat.com.br \\ 2 Engenheiro Civil, Mestre, Tecomat Engenharia Ltda. \\ ${ }^{3}$ Engenheiro Civil, Mestrando, Universidade Federal da Paraíba, tiago@tecomat.com.br \\ ${ }^{4}$ Engenheiro Civil, Dr, Universidade de Pernambuco, angelo@tecomat.com.br
}

Resumo: Na última década a preocupação com a durabilidade das estruturas de concreto armado e seus materiais se intensificou ainda mais, especialmente para as estruturas que estão situadas em ambientes agressivos (marítimos). Esse trabalho apresenta um estudo de caso, o qual busca mostrar o comportamento mecânico, resistência à tração direta, de barras de aço CA-50 estocadas ao ar livre e expostas a um ambiente marítimo por cerca de 3 anos. Foram executados ensaios de tração, utilizando equipamento específico, em 32 amostras coletadas em campo. Além disso, observou-se a perda de massa das barras utilizando-se solução aquosa de ácido clorídrico para remover os produtos da oxidação. Os limites de escoamento, resistência máxima, alongamento e massa de aço por metro, ficaram em conformidade com a NBR7480:2007, especificações para aço destinado a armaduras para estruturas de concreto armado. Ou seja, que todas as amostras das barras ensaiadas mantiveram suas características mecânicas preservadas diante das condições de contorno e nível de degradação encontrados neste estudo de caso.

Palavras-chave: Aço; corrosão; tração; comportamento mecânico.

Abstract: In the last decade, the concern regard to durability of the reinforced concrete structures and their materials has intensified even more, especially for the structures that are in aggressive (marine) environments. This paper presents a case which seeks to show the mechanical behavior, resistance to direct traction, of CA-50 steel bars stored outdoors and exposed to a maritime environment for about 3 years. Traction tests were performed, using specific equipment, on 32 samples collected in the field. In addition, the mass loss of the bars was observed using aqueous hydrochloric acid solution to remove the products from the oxidation. The limits of flow, maximum strength, elongation and steel mass per meter were in accordance with NBR7480: 2007, specifications for reinforcing steel for reinforced concrete structures. Thus, all samples of the bars tested maintained their mechanical characteristics preserved under the conditions and level of degradation found in this case study.

Keywords: Steel; corrosion; traction; Mechanical behavior. 
DEMÉTRIO FILHO, ET AL., AVALIAÇÃO DA RESISTÊNCIA À TRAÇÃO DE BARRAS DE AÇO CA-50 EXPOSTAS À REGIÃO LITORÂNEA. $2^{\circ}$ Simpósio Paranaense de Patologia das Construções (2० SPPC), artigo 2SPPC1036, pp. 435-447, 2017. DOI:

\section{Introdução}

Na última década a preocupação com a durabilidade das estruturas de concreto armado e seus materiais cresceu ainda mais, como por exemplo, o acréscimo de requisitos e critérios em normas brasileiras relacionadas ao concreto armado.

A norma Brasileira que rege o projeto de estruturas de concreto, NBR 6118 [1] define durabilidade como sendo a capacidade da estrutura em resistir às influências ambientais previstas e definidas em conjunto pelo autor do projeto estrutural e o contratante, no início dos trabalhos de elaboração do projeto. Lembrando que as estruturas devem conservar sua segurança estabilidade e aptidão em serviço durante o prazo correspondente a sua vida útil.

A preocupação com durabilidade toma força uma vez que a corrosão de armadura é tida até os dias de hoje como um dos principais tipos, senão o principal, de manifestação patológica que acomete as estruturas de concreto armado no Brasil e no mundo. Pesquisadores como Andrade [2], Aranha [3] e Dal Molin [4] realizaram levantamentos sobre as manifestações patológicas em concreto armado em lugares distintos do Brasil, apontando a corrosão de armaduras como a manifestação patológica que mais ocorre.

Helene [5] alerta ainda sobre a grande incidência da corrosão de armaduras em estruturas de concreto, acarretando grandes prejuízos à população (queda da adutora da Sabesp) e até mesmo causando acidentes fatais (desabamentos de marquises e lajes em balanço).

\section{Objetivo}

Tendo em vista a preocupação com a durabilidade e perda de desempenho mecânico das estruturas de concreto armado, esse artigo tem por objetivo verificar o comportamento mecânico, resistência à tração direta, de barras de aço CA-50 estocadas ao ar livre e expostas a um ambiente litorâneo por cerca de 3 anos.

\section{Aço e seu comportamento perante a corrosão}

Segundo Dias [6], o processo de produção do aço é dividido em cinco etapas: Preparo das matérias primas (coqueria e sinterização), produção do ferro gusa (alto forno), produção do aço (aciaria), refinamento e lingotamento, e conformação mecânica (laminação e trefilação).

O aço é basicamente uma liga de ferro e carbono, contendo cerca de 0,008 \% até $2,11 \%$ de Carbono, além de elementos secundários como silício, manganês, fósforo e enxofre.

Segundo Araújo [7], pode-se classificar o ferro e suas ligas pelo teor de carbono da seguinte maneira:

- Aço doce - menos de 0,2 \% de carbono;

- Aço carbono - entre 0,2 \% e 1,7\%; 
DEMÉTRIO FILHO, ET AL., AVALIAÇÃO DA RESISTÊNCIA À TRAÇÃO DE BARRAS DE AÇO CA-50 EXPOSTAS À REGIÃO LITORÂNEA. $2^{\circ}$ Simpósio Paranaense de Patologia das Construções (20 SPPC), artigo 2SPPC1036, pp. 435-447, 2017. DOI:

- Ferro fundido - entre $1,7 \%$ e $6,7 \%$.

As concentrações de carbono, bem como a presença de outros elementos, influirão nas características da liga de ferro. O aço, por exemplo, distingue-se do ferro por ser mais duro, admitir têmpera, e ser mais fusível e quebradiço. Já o ferro fundido, diferencia-se do aço doce por não ser forjável.

Em experimentos desenvolvidos por Carvalho [8], observou-se que a quantidade de carbono presente no aço tem influência na atividade corrosiva após a despassivação da armadura. Verificou-se que a atividade corrosiva aumentou em amostras com maiores teores de carbono.

Demétrio Filho [9] verificou que aços de bitolas 6,3, 8,0 e 10,0 mm, tipo CA-50, mantiveram suas características mecânicas de resistência à tração, depois de submetidos a ciclos de molhagem e secagem em água contaminada com cloretos, por cerca de 90 dias.

\section{Normatização Pertinente}

Atualmente, a NBR 7480 [10] (Aço destinado a armaduras para estruturas de concreto armado- especificação) estabelece requisitos exigidos para encomenda, fabricação e fornecimento de barras e fios de aço destinados a armaduras para estruturas de concreto armado.

Em função do estudo a ser desenvolvido a seguir, este trabalho se aterá a analisar apenas alguns itens específicos da NBR 7480, os quais são termos e definições, requisitos gerais, requisitos específicos, ensaios, configuração geométrica, características das barras e fios, e por fim, propriedades mecânicas exigíveis.

\subsection{Definições}

Segundo a norma Brasileira 7480 [10], diâmetro nominal é o valor que representa o diâmetro equivalente da seção transversal típica do fio ou da barra, expresso em milímetros.

Entende-se por massa linear nominal, a massa por unidade de comprimento do fio ou da barra de diâmetro nominal específico, expresso em quilogramas por metro.

Por fim, área nominal é o valor que representa a área da seção transversal do fio ou barra de diâmetro nominal específico, expresso em milímetros quadrados.

\subsection{Classificação}

Ainda com relação à norma citada anteriormente, classificam-se como barras os produtos de diâmetro nominal $6.3 \mathrm{~mm}$ ou superior, obtidos por laminação a quente sem processo posterior de deformação mecânica.

Classificam-se como fios aqueles de diâmetro nominal $10.0 \mathrm{~mm}$ ou inferior, obtidos a partir de fio-máquina por trefilação ou laminação a frio. 
DEMÉTRIO FILHO, ET AL., AVALIAÇÃO DA RESISTÊNCIA À TRAÇÃO DE BARRAS DE AÇO CA-50 EXPOSTAS À REGIÃO LITORÂNEA. $2^{\circ}$ Simpósio Paranaense de Patologia das Construções (2 SPPC), artigo 2SPPC1036, pp. 435-447, 2017. DOI:

Outra classificação pode ser feita com relação ao valor característico da resistência de escoamento, onde as barras de aço são classificadas nas categorias CA-25 e CA-50, e os fios de aço na categoria CA-60.

A sigla CA-25 diz: Aço para concreto armado com resistência característica de escoamento de $250 \mathrm{MPa}$. E analogamente paras as classes CA-50 e CA-60, cujas resistências características de escoamentos são $500 \mathrm{MPa}$ e $600 \mathrm{MPa}$, respectivamente.

\subsection{Defeitos}

As barras e fios de aço destinados a armaduras de concreto armado devem ser isentos de defeitos prejudiciais, tais como: esfoliação (escamas), corrosão, manchas de óleo, redução de seção e fissuras transversais.

Uma oxidação do produto pode ser admitida quando for superficial, sem comprometimento de sua conformação geométrica $(O$ grau de oxidação permitido é caracterizado quando, após sua remoção com tecido grosseiro ou escova qualquer não se observe evidências de corrosão.).

Em caso de dúvida quanto à gravidade dos defeitos observados, o material deve ser submetido a ensaios para a comprovação de suas propriedades.

\subsection{Requisitos específicos}

A massa real das barras e fios deve ser igual à sua massa linear nominal, com tolerâncias indicadas na tabela 1 (extraída da NBR 7480).

Os fios podem ser lisos, entalhados ou nervurados. Os fios de diâmetro nominal igual a $10,0 \mathrm{~mm}$ devem ter obrigatoriamente entalhes ou nervuras.

Tabela 1: Características das barras.

\begin{tabular}{|c|c|c|}
\hline $\begin{array}{c}\text { Diâmetro nominal } \\
(\mathbf{m m})\end{array}$ & \multicolumn{2}{|c|}{ Massa e tolerância por unidade de comprimento } \\
\hline Barras & Massa nominal (Kg/m) & Máxima variação permitida \\
\hline 6,3 & 0,245 & $+-7 \%$ \\
\hline 8,0 & 0,395 & $+-7 \%$ \\
\hline 10,0 & 0,617 & $+-6 \%$ \\
\hline 12,5 & 0,963 & $+-6 \%$ \\
\hline 16,0 & 1,578 & $+-5 \%$ \\
\hline 20,0 & 2,466 & $+-5 \%$ \\
\hline 25,0 & 3,853 & $+-4 \%$ \\
\hline 32,0 & 6,313 & $+-4 \%$ \\
\hline
\end{tabular}


DEMÉTRIO FILHO, ET AL., AVALIAÇÃO DA RESISTÊNCIA À TRAÇÃO DE BARRAS DE AÇO CA-50 EXPOSTAS À REGIÃO LITORÂNEA. $2^{\circ}$ Simpósio Paranaense de Patologia das Construções (20 SPPC), artigo 2SPPC1036, pp. 435-447, 2017. DOI:

Os requisitos de propriedades mecânicas de tração, no caso do aços CA-50, devem atender a uma resistência característica de escoamento de $500 \mathrm{MPa}$ e limite de resistência de 1,08 fyc, conforme NBR 7480 .

\subsection{Ensaios}

O ensaio de tração deve ser realizado de acordo com a ABNT ISO 6892 e ISO 15630-1. O comprimento inicial L0 é igual a 10 diâmetros nominais, não sendo permitido o uso de corpo de prova usinado. Vale salientar que é necessário deixarse espaço suficiente para acoplar a garra que irá prender a barra para realizar o ensaio. Ou seja, uma barra de bitola $10 \mathrm{~mm}$ terá um comprimento de $10 \times 10 \mathrm{~mm}=$ $100 \mathrm{~mm}+200 \mathrm{~mm}$ (garra) $=300 \mathrm{~mm}$ (comprimento de $30 \mathrm{~cm}$ para ensaio).

A resistência de escoamento de barras e fios de aço pode ser caracterizada por um patamar no diagrama tensão deformação ou calculada pelo valor da tensão sob a carga correspondente à deformação permanente de $0,2 \%$. As fotos do processo descrito, resumidamente aqui, estão presentes no capítulo dedicado ao estudo de caso.

\section{Corrosão}

Gentil [11] define corrosão como a deterioração de um material, geralmente metálico, por ação química ou eletroquímica do meio ambiente aliada ou não a esforços mecânicos. O autor ainda afirma que em geral, a corrosão é um processo espontâneo e está constantemente transformando os materiais metálicos de modo que a durabilidade e desempenho dos mesmos deixam de satisfazer os fins a que se destinam.

Gentil [11] ainda afirma que os processos de corrosão são considerados reações químicas heterogêneas ou reações eletroquímicas que passam geralmente na superfície de separação entre o metal e o meio corrosivo. A corrosão, segundo o autor, pode ocorrer sob diferentes formas, considerando-se a aparência ou forma de ataque e as diferentes causas e mecanismos.

Segundo Bertolini [12], os materiais metálicos em contato com ambientes agressivos estão sujeitos à corrosão. Estes materiais são empregados no setor das construções de diversas formas, desde estruturas em aço até tubulações. Em função do elemento estrutural, a corrosão pode influir na segurança estrutural, reduzindo a seção resistente dos elementos de suportes ou de junção.

A corrosão na superfície dos metais em contato com ambientes úmidos ocorre por meio de um processo eletroquímico, conforme afirma Bertolini [12]. Com relação ao processo eletroquímico, pode-se especificar quatro processos, como ilustrado na figura 1.

Uma reação anódica de oxidação do metal, que propicia a formação de produtos de corrosão e torna disponíveis elétrons na rede cristalina do metal.

Uma reação catódica, que reduz uma espécie química presente no ambiente agressivo e consome os elétrons produzidos pelo processo anódico. 
DEMÉTRIO FILHO, ET AL., AVALIAÇÃO DA RESISTÊNCIA À TRAÇÃO DE BARRAS DE AÇO CA-50 EXPOSTAS À REGIÃO LITORÂNEA. $2^{\circ}$ Simpósio Paranaense de Patologia das Construções (2० SPPC), artigo 2SPPC1036, pp. 435-447, 2017. DOI:

A circulação de corrente no metal, gerada pelo fluxo de elétrons na rede cristalina do metal.

A circulação de corrente no ambiente, produzida pela migração elétrica de íons dissolvidos na solução líquida em contato com a superfície do metal.

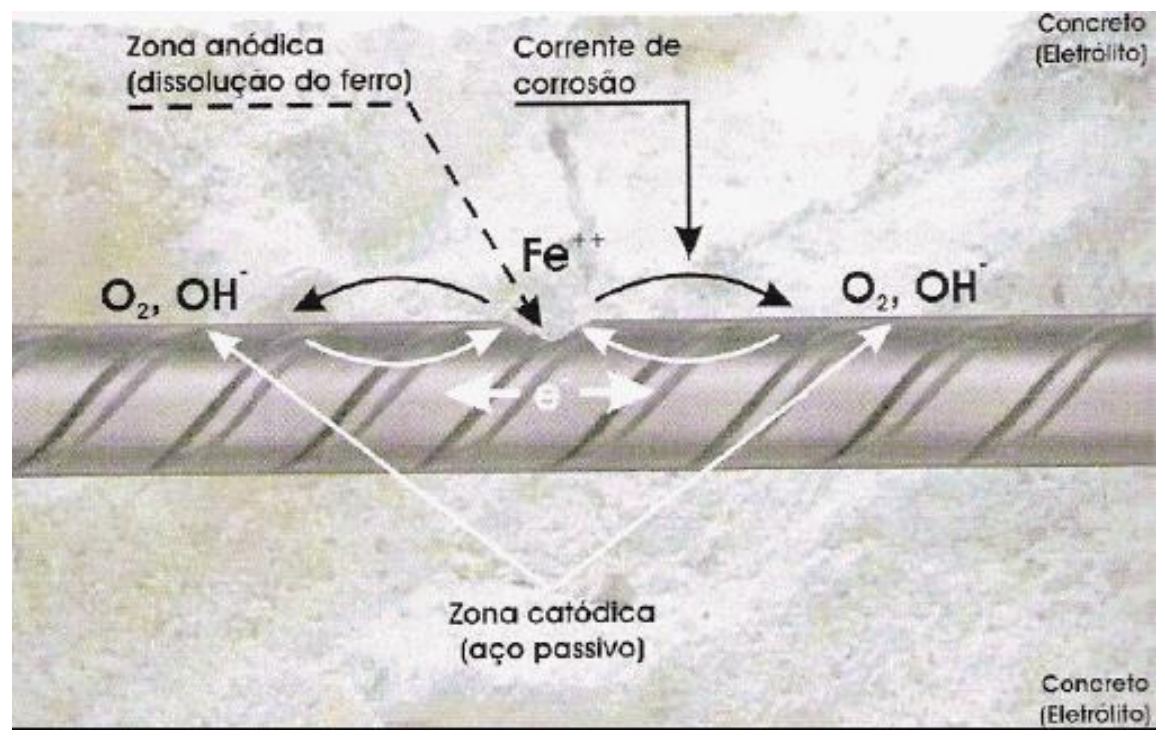

Figura 1: Exemplo do mecanismo de uma corrosão eletroquímica (CASCUDO, 2005).

Por fim, será discutida neste item a corrosão atmosférica dos aços. Segundo Bertolini [12], este tipo de corrosão pode ocorrer somente quando a superfície do material está molhada; todavia, é suficiente a formação de um véu de água produzido pela condensação da umidade ambiente.

Os efeitos deste tipo de corrosão dependem da duração da permanência do filme líquido sobre a superfície metálica, que por sua vez depende das condições de umidade locais. Em alguns casos, os produtos de corrosão são solúveis e facilmente laváveis, expondo novamente a superfície do metal. Em outros casos, pode formar camadas de óxido aderente que blinda a superfície do metal (carepa), desacelerando o avanço do fenômeno.

\section{Metodologia (Estudo de caso)}

Neste trabalho, foi realizado um estudo de caso em uma obra localizada na zona litorânea do Estado de Pernambuco, onde havia centenas de toneladas de barras de aço para concreto armado estocados no próprio canteiro ao ar livre durante cerca de 3 anos.

Em julho de 2013, foi feito um mapeamento dos locais onde as barras estavam armazenadas, no intuito de verificar quais bitolas seriam encontradas. Para tal, os locais foram divididos em grupos e posteriormente foram coletadas amostras de cada grupo (figura 2). 
DEMÉTRIO FILHO, ET AL., AVALIAÇÃO DA RESISTÊNCIA À TRAÇÃO DE BARRAS DE AÇO CA-50 EXPOSTAS À REGIÃO LITORÂNEA. $2^{\circ}$ Simpósio Paranaense de Patologia das Construções (2० SPPC), artigo 2SPPC1036, pp. 435-447, 2017. DOI:

Para verificar o comportamento mecânico das barras de aço, as amostras foram submetidas a ensaio de tração, bem como perda de massa linear nominal.

Esses ensaios têm como objetivo verificar se as barras estocadas há certo tempo ainda preservam suas propriedades mecânicas ou esse tempo de exposição e oxidação reduziram sua resistência à tração.

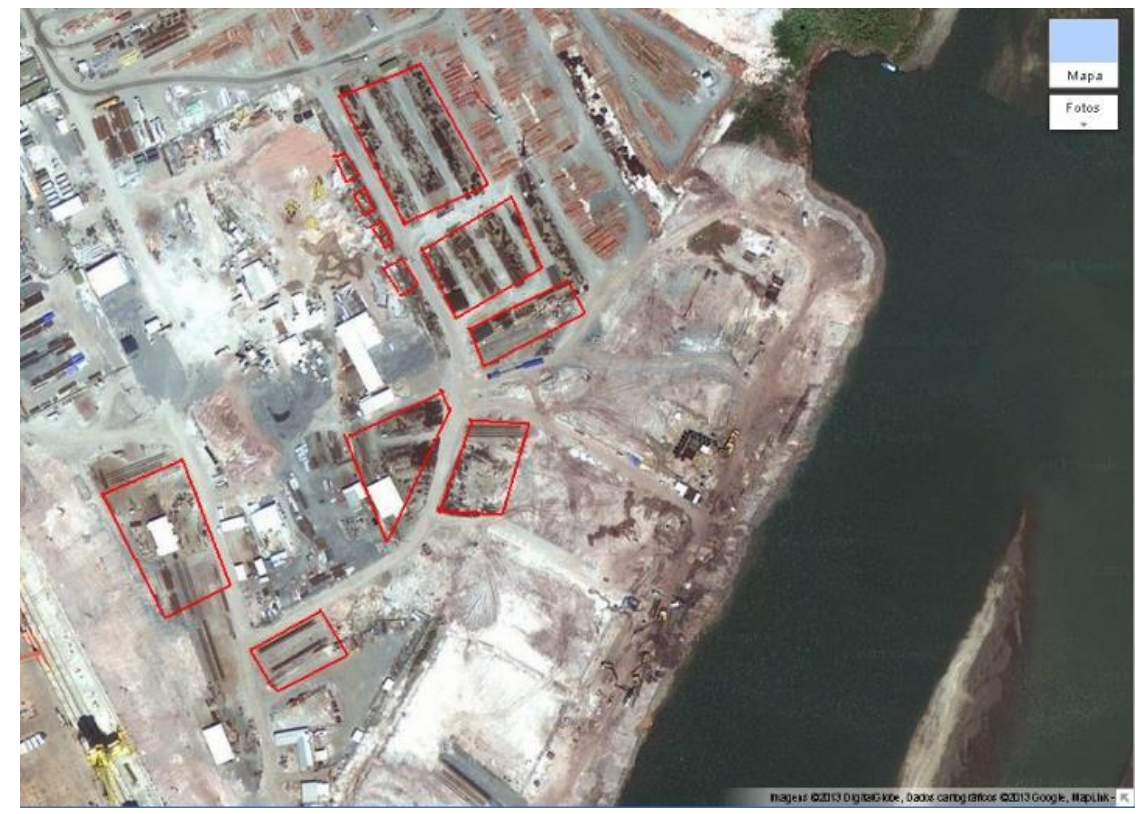

Figura 2: Croqui esquemático das divisões feitas por grupo marcados em vermelho. (Google maps, 2013).

Foram coletadas 122 barras ao todo, sendo encontradas bitolas entre $6.3 \mathrm{~mm}$ e 32 $\mathrm{mm}$. Em cada um dos grupos foram encontrados barras e estribos de bitolas diferentes, com quantidades variadas e dispostas de maneiras diferentes como pode ser visto nas figuras 3 e 4 a seguir.

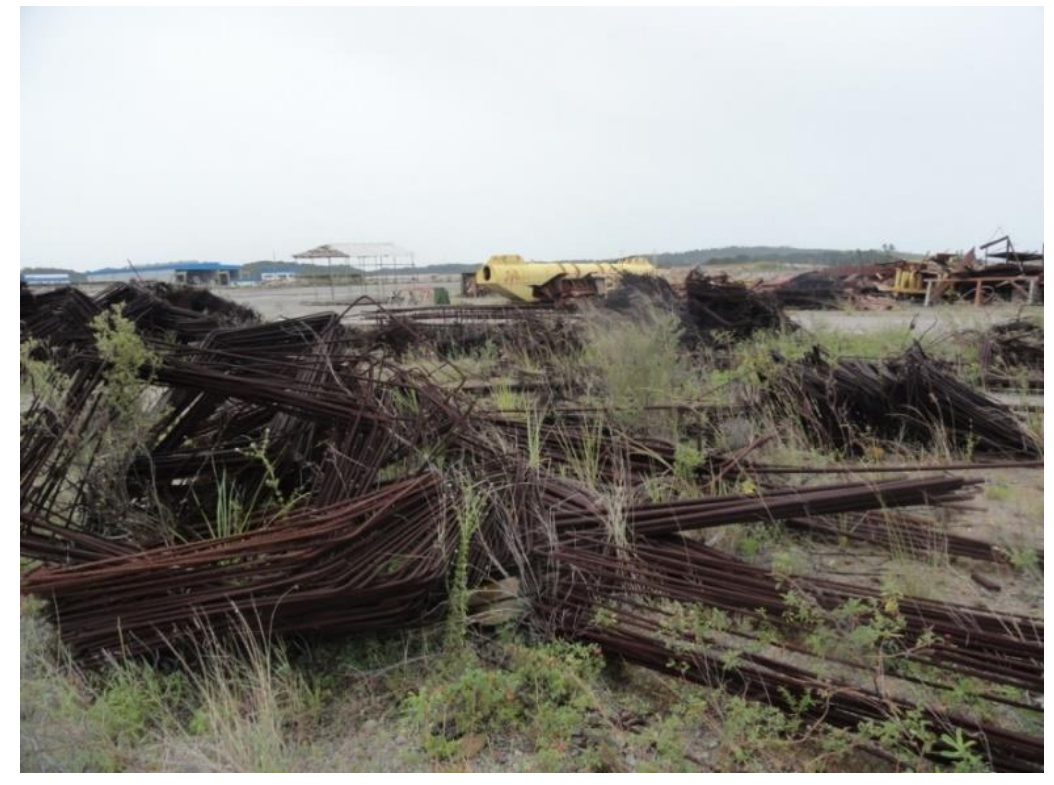

Figura 3: Visão geral de estribos e barras de aço armazenadas no grupo 7. (Autor) 


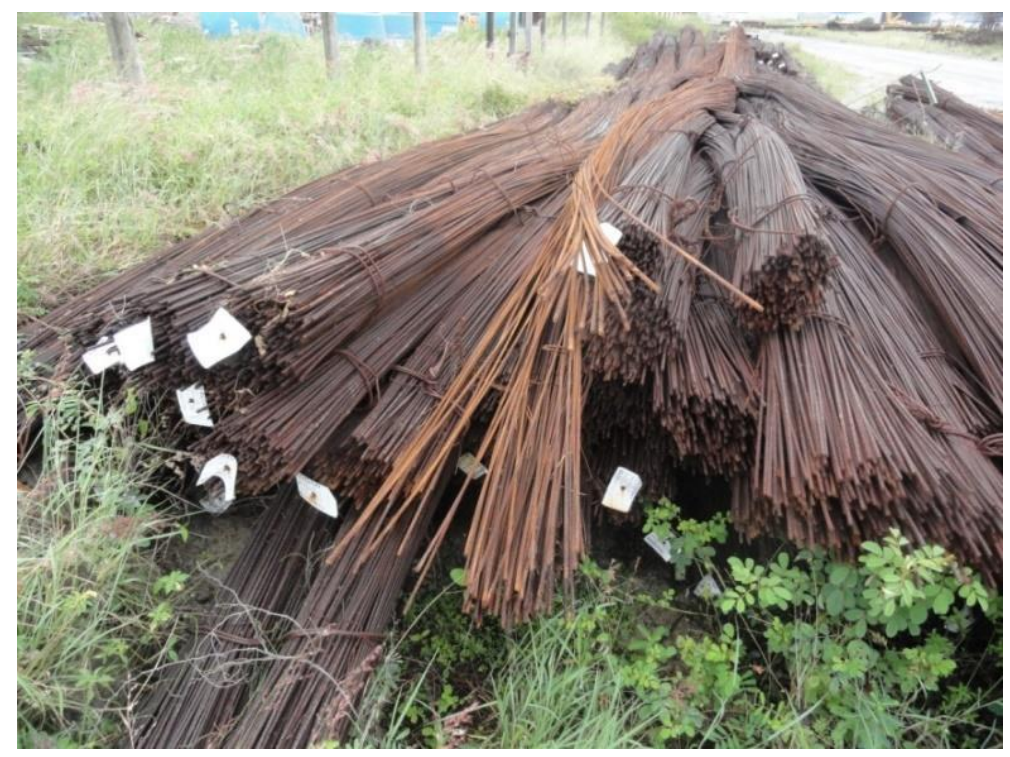

Figura 4: Barras de aço armazenadas no grupo 8. Bitolas de $10 \mathrm{~mm}$ e $6,3 \mathrm{~mm}$. (Autor.)

Do total de 122 barras coletadas, foram escolhidas 4 (quatro) barras de cada bitola, priorizando as que estavam, visualmente, em maior estado de deterioração superficial. Com isso, foram separadas 32 barras para serem ensaiadas e analisadas. A metodologia e os ensaios estão descritos seguir.

\subsection{Ensaio de Tração}

O ensaio de resistência à tração foi realizado segundo a NBR ISO 6892:2002Materiais metálicos - Ensaio de tração à temperatura ambiente, no qual as barras foram cortadas em tamanhos diferentes de acordo com a bitola (figura 10), pesadas para se obter a massa por unidade de comprimento (figura 11) e por fim foram ensaiadas à tração em equipamento específico (EMIC DL-60000) (figura 12). As amostras foram ensaiadas em laboratório especializado.

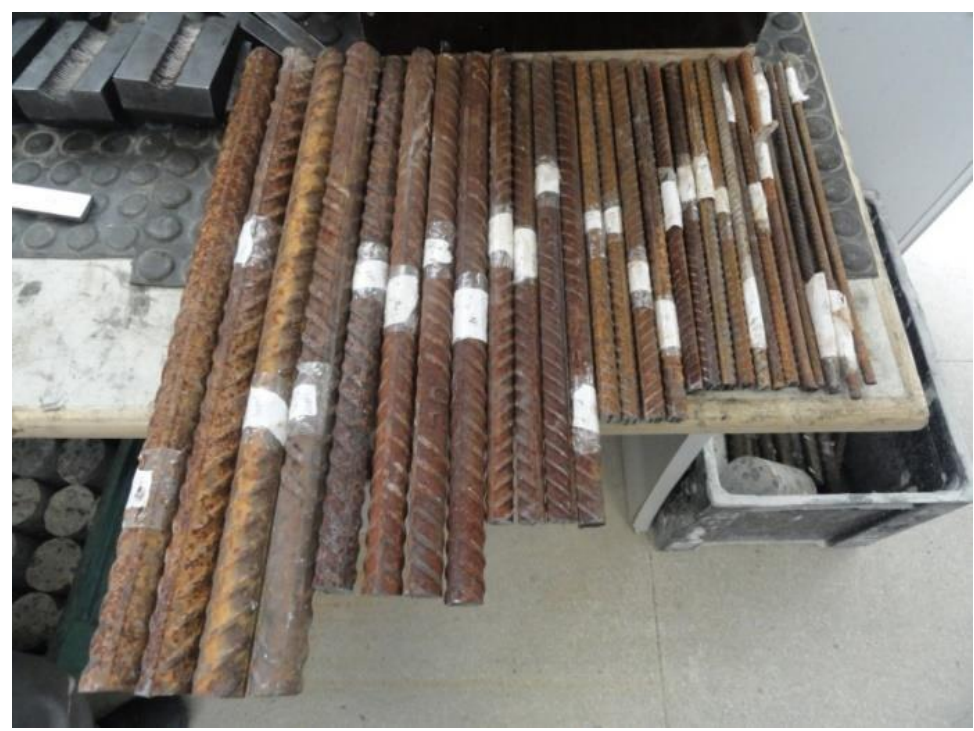

Figura 5: Barras cortadas nos respectivos tamanhos para a realização do ensaio de tração. (Autor). 


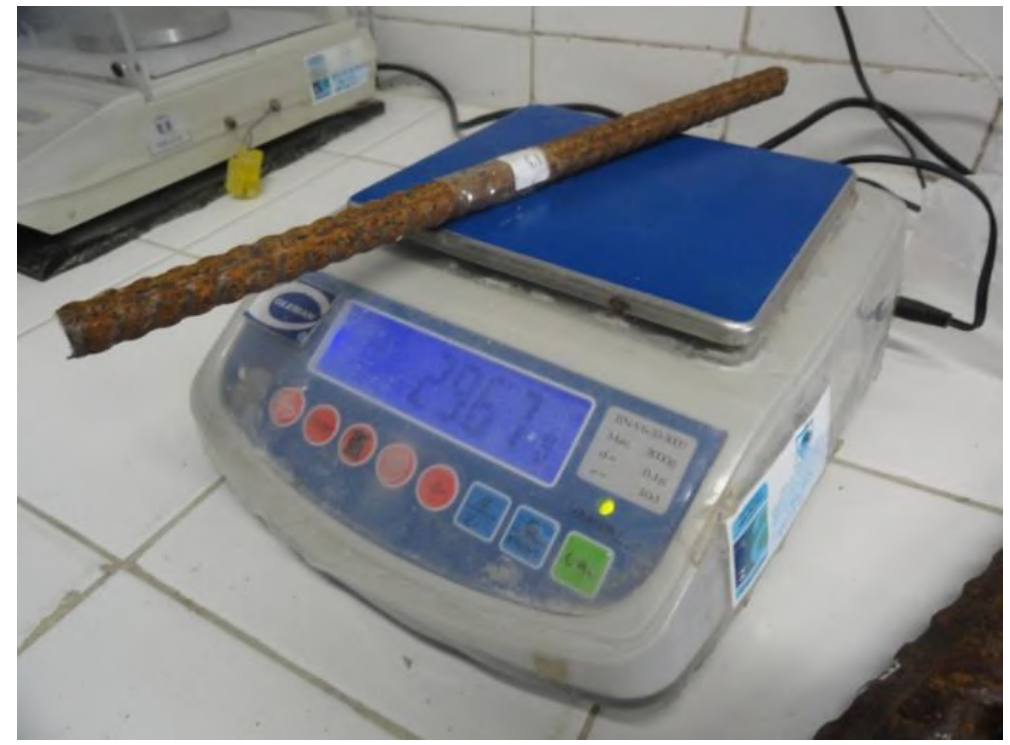

Figura 6: Pesagem das barras para análise da massa por unidade de comprimento. (Autor).

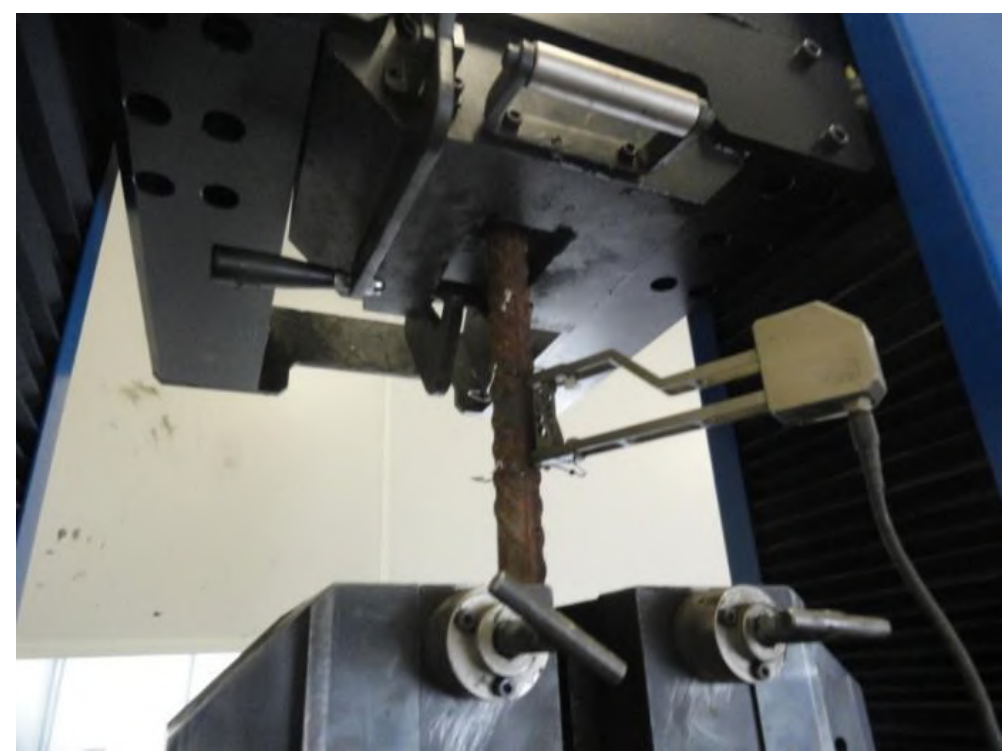

Figura 7: Equipamento que exerce esforço de tração na barra e extensômetro para medir o alongamento (Autor).

\subsection{Ensaio de Perda de massa em barras de aço}

Para a realização deste ensaio foi utilizado uma solução de ácido clorídrico $(\mathrm{HCl})$ e água na proporção de 1:1, conforme Mota, [13], figura 9, com o intuito de limpar a camada superficial do produto de oxidação e comparar a massa da barra por unidade de comprimento, com o valor nominal prescrito na norma brasileira.

As barras foram imersas na solução descrita acima por volta de 15 minutos, depois lavadas com água corrente e escovadas com escova de aço (figura 10). Em seguida foram secas com auxílio de um secador e então pesadas com balança de precisão de $0,1 \mathrm{~g}$ (figura 11). 
DEMÉTRIO FILHO, ET AL., AVALIAÇÃO DA RESISTÊNCIA À TRAÇÃO DE BARRAS DE AÇO CA-50 EXPOSTAS À REGIÃO LITORÂNEA. $2^{\circ}$ Simpósio Paranaense de Patologia das Construções (2० SPPC), artigo 2SPPC1036, pp. 435-447, 2017. DOI:

10.4322/2SPPC.2017.036

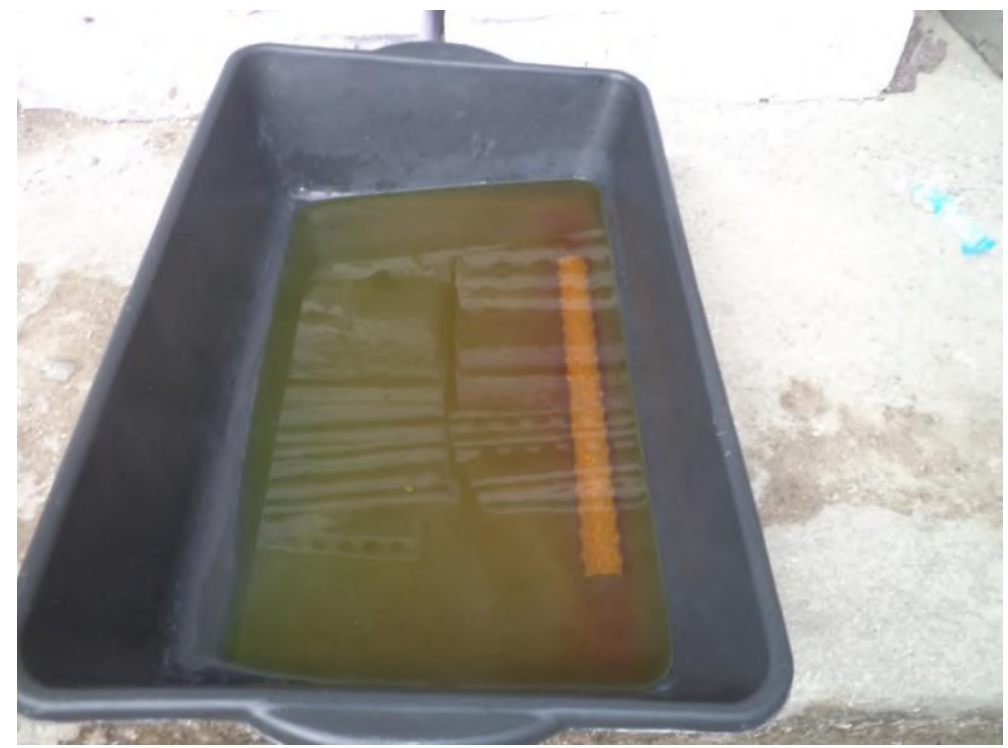

Figura 8: Limpeza das barras com solução de ácido clorídrico e água. (Autor).

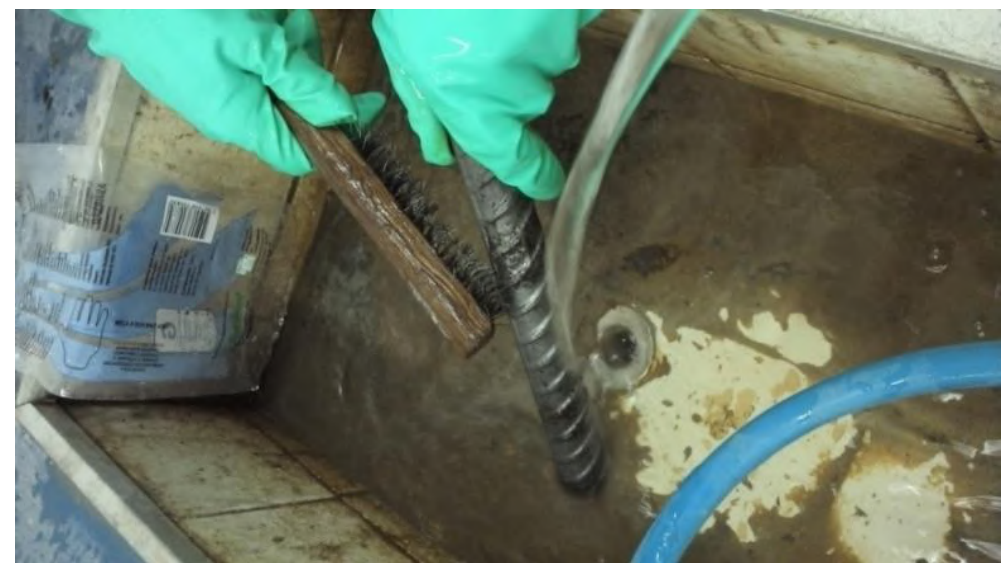

Figura 9: Limpeza com água corrente e escova de aço, podendo ser observado o aspecto da barra (cor original). (Autor).

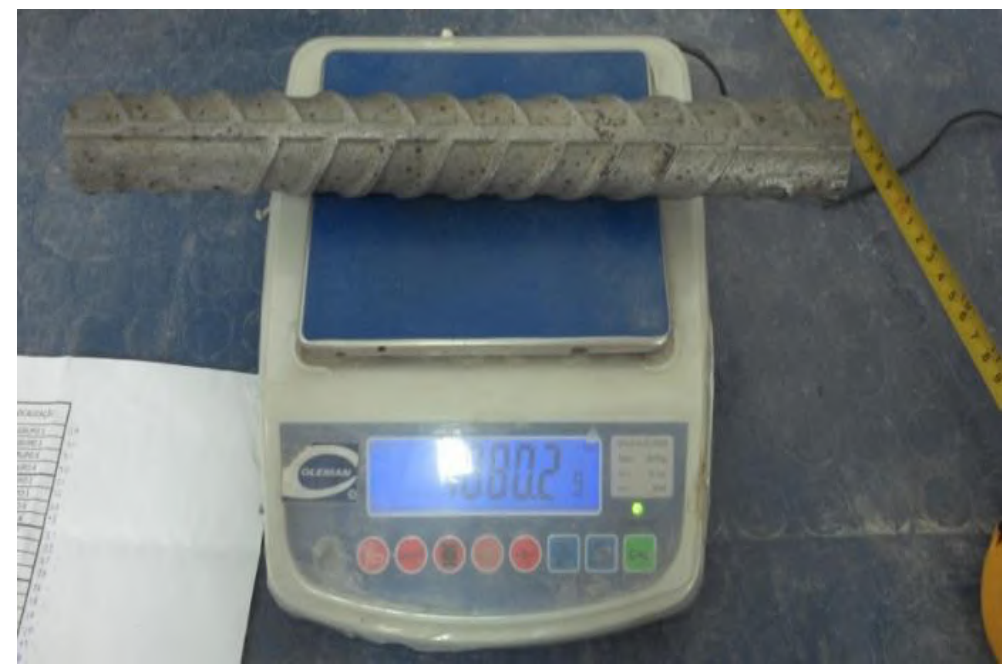

Figura 10: Pesagem final da barra. (Autor). 
DEMÉTRIO FILHO, ET AL., AVALIAÇÃO DA RESISTÊNCIA À TRAÇÃO DE BARRAS DE AÇO CA-50 EXPOSTAS À REGIÃO LITORÂNEA. $2^{\circ}$ Simpósio Paranaense de Patologia das Construções (2० SPPC), artigo 2SPPC1036, pp. 435-447, 2017. DOI:

\section{Resultados e Discussões}

\subsection{Ensaio de Tração}

Tabela 2: Resultado do ensaio de tração da segunda amostragem, realizado nas 32 amostras escolhidas.

\begin{tabular}{|c|c|c|c|c|c|c|c|}
\hline № & $\begin{array}{l}\text { Identificação } \\
\text { da amostra }\end{array}$ & $\begin{array}{l}\text { Classe } \\
\text { do aço }\end{array}$ & $\begin{array}{c}\text { Diâmetro } \\
(\mathrm{mm})\end{array}$ & $\begin{array}{c}\text { Massa por } \\
\text { unidade de } \\
\text { comprimento } \\
(\mathrm{Kg} / \mathrm{m})\end{array}$ & $\begin{array}{c}\text { Limite de } \\
\text { escoamento } \\
\mathrm{fy}_{\mathrm{y}}(\mathrm{MPa}) \\
\text { Limite } \\
\text { mínimo: } 500 \\
\mathrm{MPa}\end{array}$ & $\begin{array}{c}\text { Limite de } \\
\text { Resistência } \\
\text { fst }(\mathrm{MPa}) \\
\text { Limite } \\
\text { mínimo: } \\
1,08 \mathrm{fy}_{\mathrm{y}}\end{array}$ & $\begin{array}{c}\text { Alongamento } \\
(\%) \\
\text { Limite } \\
\text { mínimo : } \\
>8\end{array}$ \\
\hline 1 & Grupo 3 & CA-50 & 25 & 3,811 & 570,9 & 745,9 & 15,2 \\
\hline 2 & Grupo 3 & CA-50 & 25 & 3,743 & 535,0 & 718,5 & 14,0 \\
\hline 3 & Grupo 1 & CA-50 & 25 & 3,728 & 555,1 & 683,9 & 16,0 \\
\hline 4 & Grupo 6 & CA-50 & 25 & 3,864 & 581,1 & 718,7 & 14,4 \\
\hline 5 & Grupo1 & CA-50 & 20 & 2,469 & 548,2 & 658,7 & 19,0 \\
\hline 6 & Grupo1 & CA-50 & 20 & 2,455 & 554,1 & 660,4 & 15,0 \\
\hline 7 & Grupo1 & CA-50 & 20 & 2,473 & 599,6 & 718,7 & 18,5 \\
\hline 8 & Grupo1 & CA-50 & 20 & 2,491 & 573,6 & 699,7 & 18,5 \\
\hline 9 & Grupo 6 & CA-50 & 16 & 1,564 & 585,8 & 727,7 & 20,0 \\
\hline 10 & Grupo 10 & CA-50 & 16 & 1,569 & 595,6 & 734,9 & 18,1 \\
\hline 11 & Grupo 5 & CA-50 & 16 & 1,560 & 577,4 & 692,7 & 19,4 \\
\hline 12 & Grupo 5 & CA-50 & 16 & 1,557 & 581,4 & 697,2 & 18,8 \\
\hline 13 & Grupo 1 & CA-50 & 12,5 & 0,983 & 651,5 & 759,1 & 8,8 \\
\hline 14 & Grupo1 & CA-50 & 12,5 & 0,987 & 658,2 & 766,4 & 10,4 \\
\hline 15 & Grupo11 & CA-50 & 12,5 & 0,974 & 634,7 & 743,5 & 8,8 \\
\hline 16 & Grupo11 & CA-50 & 12,5 & 0,977 & 604,8 & 724,6 & 11,2 \\
\hline 17 & Grupo 8 & CA-50 & 10,0 & 0,621 & 620,6 & 745,2 & 10,0 \\
\hline 18 & Grupo8 & CA-50 & 10,0 & 0,621 & 635,0 & 762,0 & 13,0 \\
\hline 19 & Grupo 1 & CA-50 & 10,0 & 0,637 & 646,2 & 719,9 & 12,0 \\
\hline 20 & Grupo 4 & CA-50 & 10,0 & 0,611 & 612,8 & 717,7 & 14,0 \\
\hline 21 & Grupo1 & CA-50 & 8,0 & 0,393 & 655,0 & 740,7 & 18,8 \\
\hline 22 & Grupo 1 & CA-50 & 8,0 & 0,395 & 661,1 & 790,1 & 15,0 \\
\hline 23 & Grupo4 & CA-50 & 8,0 & 0,405 & 598,8 & 682,8 & 16,3 \\
\hline 24 & Grupo4 & CA-50 & 8,0 & 0,393 & 637,6 & 734,8 & 13,8 \\
\hline 25 & Grupo1 & CA-50 & 6,3 & 0,246 & 510,5 & 743,9 & 11,1 \\
\hline 26 & Grupo1 & CA-50 & 6,3 & 0,249 & 610,9 & 824,4 & 15,9 \\
\hline 27 & Grupo8 & CA-50 & 6,3 & 0,243 & 555,6 & 735,1 & 12,7 \\
\hline 28 & Grupo 4 & CA-50 & 6,3 & 0,246 & 609,2 & 879,4 & 14,3 \\
\hline 29 & Grupo 9 & CA-50 & 32 & 6,3205 & 634 & 812 & 28,8 \\
\hline 30 & Grupo 9 & CA-50 & 32 & 6,5050 & 577 & 736 & 28,8 \\
\hline 31 & Grupo 1 & CA-50 & 32 & 6,3912 & 580 & 728 & 25,0 \\
\hline 32 & Grupo 6 & CA-50 & 32 & 6,3848 & 592 & 757 & 28,1 \\
\hline
\end{tabular}

Os resultados das amostras descritas na tabela 2 atendem a todos os requisitos de limite de escoamento, resistência e alongamento exigidos pela NBR 7480 [9]. Quanto à massa por unidade de comprimento, os valores obtidos também estão dentro dos limites normativos.

Mesmo com o resultado favorável quanto aos limites normativos de perda de massa, deve-se atentar para a possibilidade da existência de barras dentro das áreas de estocagem, que podem apresentar seções transversais abaixo do limite normativo. 
DEMÉTRIO FILHO, ET AL., AVALIAÇÃO DA RESISTÊNCIA À TRAÇÃO DE BARRAS DE AÇO CA-50 EXPOSTAS À REGIÃO LITORÂNEA. $2^{\circ}$ Simpósio Paranaense de Patologia das Construções (2० SPPC), artigo 2SPPC1036, pp. 435-447, 2017. DOI:

\section{Considerações finais}

Todas as amostras das barras ensaiadas indicaram que o aço estocado manteve suas características mecânicas preservadas, ou seja, os seus limites de escoamento, de resistência, de alongamento atenderam às tolerâncias normativas exigidas pela NBR 7480 [9].

Com relação ao ensaio para determinação da massa por unidade de comprimento, apesar o considerável período de exposição das barras, as perdas de massa das amostras estão dentro dos limites normativos. Contudo, a perda de seção não é uniforme, sendo prudente proceder a avaliação amostral do desbitolamento das barras, através de uma inspeção visual e de paquímetro.

\section{Referências}

[1] Associação Brasileira De Normas Técnicas. NBR 6118: Projeto de Estruturas de concreto-Procedimento. Rio de Janeiro, 2014.

[2] Andrade, J. J. O.. Durabilidade das estruturas de concreto armado: análise das manifestações patológicas nas estruturas no estado de Pernambuco. Dissertação (Mestrado), Universidade Federal do Rio Grande do Sul, Porto Alegre, 1997.

[3] Aranha, P.M.S.. Contribuição ao estudo das manifestações patológicas em estruturas de concreto armado na região amazônica. Dissertação (Mestrado), Universidade Federal do Rio Grande do Sul, Porto Alegre, 1994.

[4] Dal Molin, D.C.C. Fissuras em estruturas de concreto armado: análise das manifestações típicas e levantamento de casos ocorridos no estado do Rio Grande do Sul. Dissertação Mestrado em Engenharia - Curso de Pós Graduação em Engenharia Civil, Universidade Federal do Rio Grande do Sul, Porto Alegre, 1988.

[5] Helene, P. R. L.. Corrosão em estruturas de concreto armado: Teoria, controle e Métodos de análise. Cap. 1 (Introdução).1ํㅡㄹ. Ed.; Rio de Janeiro, 2014.

[6] Dias, L. A. M.. Estruturas de aço: Conceitos, técnicas e linguagem. 2 ed. São Paulo, Zigurate editora, 1998. $459 \mathrm{p}$

[7] Araújo, L. A. D. O. B. D.. Livro de matérias de construção, 2 / coordenador L.A. Falcão Bauer; revisão técnica João Fernando Dias. $-5^{\text {a }}$ Ed.-Rio de Janeiro: LTC, 2008.

[8] Carvalho, L. G. S.. Resistência à corrosão dos aços CA24 e CA50 frente à ação dos cloretos. Dissertação de Mestrado apresentada à Universidade Federal de Goiás. Goiânia, 2014.

[9] Demétrio Filho, A. de A.. Avaliação do concreto celular sob processo de corrosão de armadura. Dissertação de Mestrado apresentada ao programa de Pós-Graduação em Engenharia Civil da Universidade de Pernambuco. Recife, $\mathrm{Pe}, 2016$. 
DEMÉTRIO FILHO, ET AL., AVALIAÇÃO DA RESISTÊNCIA À TRAÇÃO DE BARRAS DE AÇO CA-50 EXPOSTAS À REGIÃO LITORÂNEA. $2^{\circ}$ Simpósio Paranaense de Patologia das Construções (2० SPPC), artigo 2SPPC1036, pp. 435-447, 2017. DOI:

[10] Associação Brasileira De Normas Técnicas. NBR 7480:2007 Aço destinado a armaduras para estruturas de concreto armado - Especificação. Rio de Janeiro. 2007.

[11] GentiL, V.. Corrosão, 6ª Ed.,editora LTC, Rio de Janeiro, 2011.

[12] Bertonili, L..Materiais de Construção- Patologia, Reabilitação, Prevenção. $1^{\mathrm{a} e}$ ed., Oficina de Textos, 2010.

[13] Mota, A. C. M.. Avaliação da presença de cloretos livres em argamassa através do método colorimétrico de aspersão da solução de nitrato de prata. Dissertação apresentada ao curso de pós- graduação em engenharia civil da escola politécnica de Pernambuco para obtenção do título de mestre em engenharia. Recife, (2011). 